\title{
Factors of the Kaingang culture which influence care for the older adult: the view of the health professional ${ }^{1}$
}

\author{
Leidyani Karina Rissardo² \\ Aline Cardoso Machado Moliterno ${ }^{3}$ \\ Ana Carla Borghi4 \\ Lígia Carreira ${ }^{5}$
}

\begin{abstract}
Objective: to describe the health professionals' perception in relation to the factors of the Kaingang culture which influence the undertaking of healthcare practices with the elders in this ethnic group. Method: descriptive research with a qualitative approach, grounded in the ethnographic method, undertaken with ten health professionals who work in the Indigenous Territory in Faxinal, in the Brazilian state of Paraná. The data was collected in the period November 2010 to February 2012 through interviews and participant observation, and was analyzed in the light of the Transcultural Nursing Theory. Results: evidence was found that the Kaingang culture has a strong influence on the professional care for the older adult, principally due to the cultural strangeness of certain customs, aspects which limit the health care for such older adults being listed. Conclusion: knowledge of the influences on the care can contribute to the forming of a framework of information relevant to the professional in the provision of care for the Kaingang older adults.

Descriptors: Delivery of Health Care; Health of Indigenous Peoples; Aged; Culture; Transcultural Nursing.
\end{abstract}

\footnotetext{
${ }^{1}$ Supported by Fundação Araucária, process \# 197/2010.

2 MSc, RN, Prefeitura Municipal de Maringá, Maringá, PR, Brazil.

${ }^{3}$ MSc, Assistant Professor, Departamento de Enfermagem, Universidade Estadual de Maringá, Maringá, PR, Brazil.

${ }^{4}$ Master's student, Departamento de Enfermagem, Universidade Estadual de Maringá, Maringá, PR, Brazil.

${ }^{5} \mathrm{PhD}$, Adjunct Professor, Departamento de Enfermagem, Universidade Estadual de Maringá, Maringá, PR, Brazil.
}

Corresponding Author:

Leidyani Karina Rissardo

Rua Doutor Miguel Ferreira, 117

Zona 7

CEP: 87030-300, Maringá, PR, Brasil

E-mail: ka_rissardo@hotmail.com
Copyright @ 2013 Revista Latino-Americana de Enfermagem This is an Open Access article distributed under the terms of the Creative Commons Attribution Non-Commercial License (CC BY-NC).

This license lets others distribute, remix, tweak, and build upon your work non-commercially, and although their new works must also acknowledge you and be non-commercial, they don't have to license their derivative works on the same terms. 


\section{Introduction}

The ageing of the indigenous population is an emerging theme for Brazilian and international research in the areas of geriatrics and gerontology, as a result of there being few studies which specifically address this part of the population. The relevance of studies directed at attention to the indigenous population is pertinent when one bears in mind that inherited beliefs and knowledges, expressed in symbolic forms through which people communicate, perpetuate and develop their knowledge and activities, shape the individual's culture, which in its turn, directly influences the thoughts, decisions and actions referent to the care ${ }^{(1-2)}$. Although the indigenous older adult shares those needs which are universal in the ageing process, one must remember that cultural roots directly influence care practices; and this being so, the care given must take such aspects into account.

Consequently, in order to care for an individual, in addition to technical and scientific knowledge, it is necessary to consider his or her beliefs and values - and for this, it is necessary to promote greater familiarity with the context experienced by the person being cared for ${ }^{(3)}$. Health professionals who face such cultural diversity must seek this cultural knowledge so as to base their care plans upon it, so as to mold these to the individual's real needs, as the more the professional is involved in the cultural universe of the person being cared for, the more efficient this process becomes ${ }^{(4)}$.

It is evident that insertion into the culture of such a population in professional care practice has shortcomings, as this has its own system of beliefs and customs which also influence how the care is provided. For this reason, it is essential for there to be studies which encourage such perspectives, considering the health professionals' possibilities and limitations in care provision in the light of the population's cultural diversity.

In view of the need to investigate the influence of the indigenous older adults' cultural context on the professional care provided to them, and of the fact that the largest indigenous population in the south region of Brazil is the Kaingang ethnic group, which is also one of the five largest ethnic groups in Brazil(5), the question is asked: What are the factors of the Kaingang culture which influence the process of professional care for the older adult from this ethnic group? In spite of research already carried out focussing on indigenous people's health, it was observed that how health professionals in the Indigenous Territories (ITs) work, and what they face and perceive in their work in care provision to the indigenous older adult, have been little discussed (6-9)

The experience with the indigenous population through surveys, and the knowledge gap found in relation to the various views of the health team in assisting this population, were behind the undertaking of this study, which aims to describe the health professionals' perception regarding the factors of the Kaingang culture which influence the carrying-out of health care practices for older adults of this ethnic group.

\section{Methodology}

This study is descriptive, with a qualitative approach, and is grounded in the ethnographic method. Ethnography provides a "dense description" of the context and the integration of information from various actors who work in the same micro-reality, a stage for interactions and conflicts $^{(1,10)}$. In this way, this study had, as its focus, the observation of, and participation in, the daily routine of the professionals in the provision of care to the Kaingang elders.

The research was carried out in the Indigenous Territory of Faxinal (ITF), situated in the Center-South Region of the state of Paraná, covering approximately 600 inhabitants of the Kaingang ethnic group. The data was collected in the period November 2010 - February 2012, through participant observation in conjunction with interviews held with all the professionals in the Multidisciplinary Team for Indigenous Health (EMSI). The EMSI is composed of a nurse, a dentist, a doctor, a nursing technician, an auxiliary nurse, an indigenous health worker (AIS), an indigenous sanitation worker (AISAN), and a driver, there being a total of ten professionals. A further four key informants were chosen, the criteria of eligibility being a broad knowledge in relation to the Kaingang culture and a long period of insertion in the ITF.

In addition, periods spent by the professionals with the community were also observed, such as soccer matches, funerals and celebrations of religious rites. The interviews were held in order to complement and validate the perceptions obtained through the participant observation, and were recorded on MP4 devices and later transcribed. Notes in the researchers' field diaries were also adopted as data records. All the information was compiled and analyzed in accordance with the model of ethnonursing proposed by Madeleine Leininger, which uses four stages: 1) reporting of the data collected, described and documented; 2) identification 
and classification of the component descriptors; 3) analysis of the contextual pattern and principal themes; theoretical inferences and formulations; 4) validation of the data. This process of analysis was initiated along with the data collection, allowing the data to be validated while still in the research field(2)

This study was considered by the National Commission for Research Ethics (CONEP), and obtained a favorable decision from CONEP no 760/2010. It respected the ethical precepts of Resolution 196/96. Two copies of the Terms of Free and Informed Consent were signed, one being handed to the participants, and the other remaining with the researchers. In relation to the differentiation of the subjects and the safeguarding of their identities, the informants were identified by the letter ' $P$ ' (for 'professional') accompanied by an Arabic number (P1 to $P 10)$, while the key informants were identified with the letters 'KI' (KI1 to KI4).

\section{Results and Discussion}

\section{Learning about the study's actors - Brief characterization of the health professionals}

The EMSI is contracted through a selection process, renewed on an annual basis, carried out through a tertiarized company which provides services to the Special Secretariat for Indigenous Health (SESAI). In the case of the AIS, these are contracted by the same company, although rather than participating in the selection test, they are indicated by the chief or by the leaders linked to him, reinforcing what has been described in regard to the sovereignty of the chief in the IT as well as the possibility of having him as an ally of the EMSI ${ }^{(11)}$.

Five were female, eight were married and half had children. The minimum age was 22 , and the maximum was 67. In regard to education, three had higher education (the doctor, the nurse and the dentist); two had done the vocational course as auxiliary nurses or nursing technicians; another four had finished high school, and one had not. The professionals with vocational courses, and those with higher education, had an average of 14.2 years of training. The professionals had, on average, 6.8 years of service in the IT health team, the minimum being five months, and the maximum, 28 years. Nine professionals had a weekly workload of 40 hours, and seven worked exclusively in the ITF, this being the first job for three; of those with previous professional experience, only two had worked with the indigenous population before.
Being present at the work of this professional team during the provision of care to the Kaingang elders allowed the construction of a thematic category: Cultural diversity and its impact on the professional care given to the Kaingang older adult, divided into two subcategories: "The professional's unfamiliarity in the face of the behaviors of, and understanding of, the Kaingang culture" and "Caring in Kaingang families: consequences for professional assistance to the older adult". These will be described below.

\section{Cultural diversity and its impact on the professional care given to the Kaingang older adult}

The unfamiliarity of the health professional in the face of the behaviors and understanding of the Kaingang culture

Working with a population with distinct cultural characteristics is a challenge for the professional in regard to understanding, and adapting to, new ways of caring. This observation was possible, in particular, based on observation of the care directed at the elderly population of the IT researched, as the elders were shown to be the guardians of the customs of the old Kaingang of the region.

The use of this ethnic group's language predominates in the ITF, as a result of which, in relation to the various cultural barriers observed between the health professionals and the indigenous people during the research, communication difficulties caused by this situation stand out. The subjects of adult age showed that, even not speaking Portuguese fluently, they could express themselves and make themselves understood in that language, thus being considered bilingual; however, the older adults had great difficulty in understanding and expressing themselves in a language other than their own, which is not understood by the majority of health professionals.

It's harder to talk with the older adults, some don't speak Portuguese well, they only know what they need to: hi, bye, it hurts [...] If an elder comes to the Basic Health Center (UBS), you have to have an AIS to be able to treat them, because the AIS can translate what the elder is saying (P4).

The majority of the elderly don't speak Portuguese, only Kaingang, so we're always calling an AIS to translate what they're saying (P1).

The use of the mother tongue is a way of preserving not only traditions, but mainly the Kaingang identity(11) In this way, although the language barrier appears as a limiting factor in assistance to this population, it is important to overcome it without the imposition 
of another language, so as to respect this people's origins and identity. This need is perceived when one reflects on the communication process's importance in the care, and how prejudicial inefficiency in it is to the care for individuals. As a strategy for strengthening this process, the AIS was identified as a fundamental element in the reduction of confusion caused by the different languages used by the indigenous people and the health professionals.

The AIS emerges as an element facilitating communication between the indigenous population and the EMSI, given that communication represents one of the main pillars in the advance of healthcare towards humanized care ${ }^{(12)}$. Thus, language is identified as one of the essential factors for improving communication and, as a consequence, healthcare, as it is through this that the professional is able to understand individuals' needs and thus adapt his or her actions. Although the AIS is essential to the process of communication and overcoming of the language barrier, the need is observed to train the team to know the Kaingang language as a means of facilitating dialog between the professional and the older adult, and thus to build links based in the exchange of information, given that limited ability in the language can be interpreted by the indigenous peoples as prejudice, thus negatively influencing the quality of the care ${ }^{(13-14)}$.

Besides the linguistic impasse, one may observe culturally-learnt and undertaken customs which are, initially, evidenced as risk factors for the health conditions of the Kaingang elders. Among the cultural customs of the elderly Kaingang reported by the health professionals, one can highlight (1) the maintenance of a small fire in the middle of their homes; (2) teeth sharpened to a point; (3) variety of eating habits (4) the attitude of the older Kaingang adults in regard to the care process (5) the attribution to the white person of the power to cure. The prolonged exposure to the smoke is evidenced as a risk factor for the development of respiratory illnesses. In these circumstances, the professional can give guidance as to the consequences of the practice; however, it is necessary to consider this habit's cultural relevance.

The older ones have the custom of having a fire going inside their houses. So, we turn up explaining that it's bad to stay in the smoke a lot, it's bad for your breathing, but that's complicated, because they're accustomed to it, they've lived like that since their childhood, who are we to take them out of their smoke? [...] you have to be cautious, because it's their culture, that's why it's complicated $[. .$.$] we can't change their culture. (P6).$
Fire, for the Kaingang, besides bringing heat to their environment, allows the preservation of and the strengthening of the spirit(5). On the other hand, it is known that the smoke contributes to the occurrence of respiratory conditions, which directly interfere with the older adult's health. In this context, the custom's relevance must be taken into account by the health professional, so as to ensure that the care may be provided with a reduction in conflicts and/or stress to the person receiving $i t^{(2)}$, and to promote interventions as well adapted as possible to the changes required for there to be evolution in the quality of the health of the Kaingang older adult.

In relation to the Kaingang habit of sharpening their teeth to points, it was evidenced that the health professionals do not interfere in this practice; but one may also observe apprehension in the face of the harm caused by this culturally-determined conduct to the Kaingang elders' oral health.

When I started working here, I found it kind of strange. I made them a whole load of dentures, and handed them over all beautiful, but two weeks later they [the indigenous elders] came for a check-up with the false teeth all pointed [...] They had filed the ends to make them all sharp [...] this can cause fistulas, and progress to abscess. It's complicated (P3).

In the layman's view, it may be observed that the esthetics of the teeth is related to the (lack of) care with the false teeth provided; however, in the Kaingang culture, this act is explained by the comparison this people makes between their teeth and the strength of wood. As the outer parts of a tree are the most fragile, individuals from this ethnic group sharpen their teeth, leaving them pointed, such that only the central part remains, understood by them as being the strongest part ${ }^{(5)}$. It is often necessary for the professional to associate the clinical knowledge acquired during his or her training with information on the local culture, so as to understand the universality of the care which he or she provides.

Another aspect found strange by the health professionals was the eating habits of the Kaingang elders, principally in relation to the characteristics of the foods consumed by this population group.

I thought they ate fish, healthy foods [...] I worry about what they eat, because they don't eat anything like that, they eat lots of carbohydrate, like potato, cassava, flour, and pork lard. They put pork lard in everything (P9).

The low scientific production on elderly indigenous people, coupled with the restricted dissemination of what there is outside academic circles, favors an unrealistic image of the Indian as a hunter or fisherman, 
this population's reality having changed over the passing years. The reduction of the forests and the pollution of the waters have restricted such practices, and the Indians have had to substitute food groups, adapting these to what can be obtained. As their low income makes it impossible to buy meat frequently, this population's protein consumption has reduced. In addition to this, the delimitation of the indigenous territories has made it impossible to rotate crops, and the constant changes in climate have rendered the old way of practicing agriculture inviable ${ }^{(5)}$.

As a result, food is based on what is easily obtained or cultivated, the use of pork fat being kept, as it was in ancestral times. It is emphasized that pork fat is considered a valuable food in this community and is also used as currency between individuals in some situations. In this context, one can observe individuals whose diet is potentially harmful to their health - the result of the adaptation of their culture to changes which have occurred in recent decades. As well as unfamiliarity in relation to eating habits, the health professionals were also surprised by the peculiarities of the older adults' behavior during the care process:

Whatever you tell them is good, not like with whites who question everything [...] They never want to know why you gave a vaccination. Non-indigenous people ask a thousand questions, and run off to the doctor over any little thing because the person who attended them didn't do it right, or didn't know the procedure [...] The Indian doesn't say that, oh no, they don't. (P10).

The fact that the subject doesn't question the treatment is evidenced as an important characteristic of the practice. However, it can indicate a low level of empowerment in the population represented. In this situation, one may question how the indigenous older adult understands their rights in the health system, and what the true aims of the Basic Health Center in the indigenous territory may be. In the face of the confirmation of the individuals' possible submission, the need is emphasized to encourage them to discuss their feelings and perspectives, as well as their satisfaction with the service. Such measures would make it possible to consider the population's real health needs and to exchange ideas in the field of caring, bringing the traditional Kaingang care practices closer to the practices recommended by the health team ${ }^{(8,15-16)}$.

On the other hand, one may also question the possibility of a transferral of power, previously attributed to the kujá (shaman), and now belonging to the health team. If a kujá has the supernatural powers to indicate treatments, does the team have the same powers, in the perception of the Indians? This perception is supported by the belief in being cured that this population places in the health treatments offered and in inpatient treatment. It was observed that some older adults were resistant to professional assistance, but that once it had been accepted, the failure of the therapy was not accepted as emphasized by one of the health professionals.

The boy died and came back in a sealed coffin, on the doctor's orders. They went to collect the body in Curitiba. When the head of FUNAI* arrived, they [the Indians] wanted to kill him. Because if he had gone to hospital, the white man had to cure him, and they wouldn't accept any other outcome. Here in the Basic Health Center, sometimes they ask us: What did you study for? You have to cure me (P10).

This behavior of the older adult - in not accepting therapeutic failures in the care process from the health professionals - has also been described in studies with other ethnic groups, such as the Baníwa, for whom the medicines and other products of the formal health system have symbolic functions associated with the whites' magical powers; hence, these products have the power to cure, and if no cure is forthcoming, it is the fault of the professional who is providing the care(7). In view of this, it is necessary for there to be transparency in relation to each case's therapeutic possibilities. For this, it is important for the AIS to be trained to act as interlocutors in the clarification of the population's doubts and in the viabilization of the understanding that the therapeutic processes can fail. Nevertheless, the challenge faced by the health professionals is great, as it is fairly difficult to accept the possibility of failure, even when one is working with non-indigenous individuals, whose belief in a cure and in supernatural powers tends to be less.

The process of caring for an indigenous older adult is, indeed, complex, as the health professionals need, at the same time, both to preserve the Indians culture, and to avoid the worsening of their health, which requires greater flexibility in the care, there being constant maintenance, negotiation and re-standardizing of the care ${ }^{(2)}$.

Caring in Kaingang families: how it affects professional assistance to the older adult

The care provided to Kaingang elders by their families, from the perspective of the health professional, 
reflects issues which are fundamental to care, considering that the family is an important practice setting for the care, being essential for the result of the care proposed by the health professionals. In this study, it was possible to identify that an order of priority is established in the families. For example, if there is only enough food for one member of the family, it must be offered to the child; if any is left over, it is offered to the adult; and only after the adults have been satisfied is the elder remembered.

The issue of the family's care for the elderly here in the ITF is really complicated, because they [the Kaingang] stipulate that the child comes first, then the adult, and then the elderly. Sometimes there isn't any money left over from the old age pension even to buy food for the older adult, because he isn't priority, you understand? [...] We can't interfere, they [the indigenous people] don't accept us interfering, they say that's how the culture is and that's how it has to be, with all these things, with the elderly like that (P2).

The Kaingang social dynamic evidences organization which is distinct from that observed among non-Indians. Among these differences, one of the aspects that stand out is the sharing of food, which is undertaken among the components of the extended family, not just among those living in that particular house(11). The older adult appears, in this context, as the maintainer of his or her descendants, providing food for all before eating any him- or herself, suggesting the maintenance of the community over the individual. As a result of this order of priority specified by the Kaingang culture for food, the health professionals note that often the older adults present symptoms of hypoglycemia precisely from shortage of food, because the families of these older adults are generally so extended, and are made up of various individuals who have priority over them for food.

There are many cases of malnutrition among the elders, we try to help those who need food, if we have something at home or even in the Basic Health Center, we bring it for them. But it doesn't help, because it's that thing - where there's one elder, there are also seven or eight other people, and the food will last one or two days (P3).

It is thought, on the other hand, that being judgmental about the exclusion of the older adult is dangerous in itself, as each population has its peculiarities and the understanding of family relationships is essential for the identification of the social roles which each person exercises. One study on the social dynamics of the Kaingang population ratifies this assertion, in finding that the elders, in many cases, are the ones who are responsible for the support of the extended families and for the education of their grandchildren ${ }^{(11)}$. It is understood, therefore, that caring for this specific age range has a fairly peculiar aspect in regard to the care for the indigenous population, the family being the practice setting for the individual's care as much as it is for the collective care. In the determination of the social roles exercised by each person, it was evidenced that the older adult is an important carer for the family.

There's always an older adult in the families. It's the grandfather or grandmother who cares for the children [...] so, I try to advise the older people well, because they [the elders] are the ones who take care of everything. Actually, we notice that for the families, the elders have the obligation to care, rather than be cared for (P3).

There are a number of elders who care for their entire families, their old age pension is the income which supports a lot of people. They (the elders) are the pillar of the Kaingang culture $[\ldots]$ (P7).

The traditional therapeutic interventions which occurred between the individuals of this ethnic group involved the more elderly people, as these are responsible for the teaching and education of their grandchildren(17). Thus it can be seen that the older adult helps in the maintenance of the health and education of the group's members, such that this individual becomes fundamental in the care of the family as a collective. Being aware of this context, the EMSI sees these subjects as multipliers of the health actions in their families, and seeks as a result to advise the young through actions undertaken with the old. Overlooking the importance and the recognition of the culture and social roles exercised by the members of the family can establish erroneous judgments, resulting in rifts in the relationships established with the population and, consequently, in the decisions taken during the implementation of the $\operatorname{care}^{(7)}$.

In this context, it may be observed that the health EMSI limited the care to the Kaingang elder as an individual process, because it failed to include the family in the care for this member, as in understanding the above-described hierarchy in the care dynamic among the Kaingang, it is concluded that its actions are more effective when they do not involve the family in the stages of care for the older adult:

Often you can't rely on the family to take care of the elders. You can see, the elders come to the UBS alone, nobody comes to keep them company. It's difficult because everything is left to us. So the AISs, as they live here, end up being responsible for the care when the elder needs it [...] The family helps like this, when it's necessary to carry out some service or other at 
home and the elder can't wash clothes, cook, things like that; but caring, giving a bath, changing them when they need it, is very unusual (P7).

It is asked which aspect, in isolation, could be considered as harmful to the care, as the literature states that the family is an important element in the support and care for the older adult ${ }^{(11,18)}$. For this reason, it becomes essential to understand the Kaingang's dynamics and conception of care, as it is based on that that the professional will be able to understand the real meaning of care for these peoples, as the non-care observed by the EMSI can be represented as something habitual for the Kaingang, because what is expected by 'care' is expressed through different practices, conceptions and meanings.

The signification of the care is based in the everyday interactions which take place between the older adult and the family, who are held as social actors constantly influenced by stories and cultural values(18-19). One study undertaken with riparian populations showed that the care for health and for illness in the families occurs dynamically and concomitantly with the care exercised by the health professionals, thus increasing the elements which make up the complex web of meanings of the cultural care ${ }^{(20)}$

In the light of such observations, it is concluded that it is necessary to act in conjunction with these families, which requires the health professional to understand the ambiguity of the relationships and the antagonism of feelings and interests expressed by their members ${ }^{(19)}$. On the other hand, the understanding of the influence of the culture on the carrying-out of assistential actions for the Kaingang elders in the context of the ITF causes reflection on the peculiarities of the services so as to evidence the knots to be undone.

\section{Final considerations}

This study made it possible to identify how challenging it is to the professional system to carry out health care for indigenous older adults, as the specific cultural characteristics of the Kaingang elder influence the practices and strategies adopted for the process of care. Among this study's findings, the cultural aspects which stood out were the importance of the fire, having their teeth sharpened to points, the preservation of eating habits, the unquestioning acceptance of professional practices, and the transferral of the power to cure to non-indigenous persons. It also stood out that the culture is determinant in the establishment of the social roles and in the individuals' family dynamics.
This study backed up the need to investigate/ understand cultural specifics for integral and effective care. In the same way, the importance of strategies which respect the older adults' way of life, and which contribute to effective health practices, minimizing possible harm resulting from this people's customs, was clear. For this reason, as it falls to the nurse, as a member of the health team, to prepare and carry out assistential plans, understanding cultural aspects is an essential tool in theplanning of care.

In this activity, the family needs to be understood, valued and duly instrumentalized, as its participation is important as encouragement for caring for the older adult; its perceptions, expectations and understanding of the care must always be respected. The authors believe that this study's results can contribute to the transformation of the assistential practice, particularly in the care of the Kaingang older adult, through the understanding of the importance of recognizing the cultural factors which surround the health assistance for these individuals. The authors also hope that this study may serve as support for the development of research referent to the issue and projects which encourage the instrumentalization of the professionals who work in the area so as to minimize doubts referent to such cultural influences.

\section{References}

1. Geertz CA Interpretação das culturas. Rio de Janeiro: LTC; 2011.

2. Leininger M, Mcfarland MR. Culture Care diversity and universality: a worldwide nursing theory. 2nd ed. New York: Jones and Bartlett Publishers; 2006.

3. Castillo CAG, Vásquez ML. El cuidado de sí de la embarazada diabética como una via para asegurar um hijo sano. Texto Contexto Enferm. 2006;15(1):74-8. 4. Herrera EM, Posada MLA. Creencias y prácticas de cuidado de la salud de ancianos. Av Enferm. 2010;28(n. esp):61-72.

5. Faustino RC, Farias AKA, Alves JNK, Mota LT. Kaingang do Faxinal: nossos conhecimentos e nossas histórias antigas. Maringá: Eduem; 2010.

6. Diehl EE, Grassi F. Uso de medicamentos em uma aldeia Guaraní do litoral de Santa Catarina, Brasil. Cad Saúde Pública. 2010;26(8):1549-60.

7. Garnelo L, Wright R. Doença, cura e serviços de saúde. Representações, práticas e demandas Baníwa. Cad Saúde Pública. 2001;17(2):273-84. 
8. Langdon EJ, Diehl EE. Participação e autonomia nos espaços interculturais de Saúde Indígena: reflexões a partir do sul do Brasil. Saúde Soc. 2007;16(2):19-36.

9. Diehl EE, Langdon EJ, Dias-Scopel RP. Contribuição dos agentes indígenas de saúde na atenção diferenciada à saúde dos povos indígenas brasileiros. Cad Saúde Pública. 2012;28(5):819-31.

10. Deslandes SF, Gomes R. A pesquisa qualitativa nos serviços de saúde: notas teóricas. In: Bosi MLM, Mercado FJ, organizadores. Pesquisa qualitativa de serviços de saúde. Petrópolis: Vozes; 2004. p. 99-120.

11. Moliterno ACM, Padilha AM, Faustino RC, Mota LT, Carreira L. Dinâmica social e familiar: uma descrição etnográfica de famílias de idosos Kaingang. Cienc Cuid Saúde. 2011;10(4):836-44.

12. Ministério da Saúde (BR). Política Nacional de Humanização. Formação e intervenção. Brasília; 2010.

13. Mcbain-Rigg K, Veitch C. Cultural barriers to health care for aboriginal and Torres Strait Islanders in Mount Isa. Austr J Rural Health. 2011;19(2):70-4.

14. Alarcón AMM, Astudillo $P$, Barrios $S$, Rivas $E$. Política de Salud Intercultural: Perspectiva de usuarios mapuches y equipos de salud en la IX región, Chile. Rev Méd Chile. 2004;132 (9):1109-14.

15. Gil LP. Políticas de Saúde, Pluralidade Terapêutica e Identidade na Amazônia. Saúde Soc. 2007; $16(2): 48-60$.

16. Peiris D, Brown A, Cass A. Addressing inequities in access to quality health care for indigenous people. CMJA. 2008;179(10):985-6.

17. Marroni MA, Faro ACM. Sendo enfermeira de índios: relato de experiência sobre o cuidar do índio no sul do Brasil. Enferm Global. 2004;5(1):1-7.

18. Carreira L, Rodrigues RAP. Dificuldades dos familiares de idosos portadores de doenças crônicas no acesso à Unidade Básica de Saúde. Rev Bras Enferm. 2010;63(6):933-99.

19. Siles GJ, Solano RMC. Cultural history and aesthetics of nursing care. Rev. Latino-Am. Enfermagem. 2011;19(5):1096-105.

20. Carreira L, Alvim NAT. O cuidar ribeirinho: as práticas populares de saúde em famílias da ilha Mutum, Estado do Paraná Maringá. Acta Scientiarum. 2002; 24(3):791-801. 